\title{
Critical Aspects of AGC Emerging from Optimal Control to Machine Learning Techniques
}

\author{
Gulshan Sharma ${ }^{1}$ and Kabulo Loji ${ }^{2}$ \\ ${ }^{1 \& 2}$ Department of Electrical Power Engineering, Durban University of Technology, Steve Biko Campus, Durban 4001, \\ South Africa
}

\begin{tabular}{l}
\hline \hline Article Info \\
\hline Article historys: \\
Received June 5, 2019 \\
Revised Feb 11, 2020 \\
Accepted May 5, 2020
\end{tabular}

Keywords:

Automatic generation control

Classical control

Optimal control

Sub-optimal control

Adaptive and variable structure

control

Robust control

ANN \& LS-SVM control

\begin{abstract}
With the emphasis towards renewable energy lot more advancement has been done in the field of electric energy system and it is expected that future energy system may have wind power dominating control areas or hydro power be it bulk hydro or micro hydro based power generations in order to cater the rising energy demands of the modern society. Hence, automatic generation control (AGC) plays a crucial role in the modern electrical energy system in order to maintain the frequency standards to nominal value besides maintaining the power interchange between the interconnected controls areas in order to distribute value and cost effective power. This paper presents the literature survey related to some of the critical aspects of AGC such as diverse sources power generations, hydro dominating control areas, wind power based power generations and applications of flexible alternating current transmission system (FACTS) in AGC. This paper also discusses the novel control designs based on the concept of optimal control, output vector feedback, model predictive control, robust control and finally the machine learning based AGC designs are explored and the critical gaps among the available research work are well presented and discussed.
\end{abstract}

Copyright $\odot 2019$ Institute of Advanced Engineering and Science. All rights reserved.

\section{Corresponding Author:}

Dr. Gulshan Sharma,

Department of Electrical Power Engineering,

Durban University of Technology,

Steve Biko Campus, 70 Steve Biko Road, Durban 4001, South Africa.

Email: gulshanS1@dut.ac.za

\section{INTRODUCTION}

The control framework is worked in interconnected design at ostensible voltage and frequency. The support of these two parameters at the evaluated values is fundamental to realize good proficiency and least wear and tear of customer's equipment's. The frequency alteration are due to genuine mismatch between energy generation and demand though voltage variation are due to up and down requirements of reactive power within the system framework. In a control framework dynamic control adjust can be accomplished by automatic generation control (AGC) [1-5]. The most objective of AGC is to preserve zero steady-state blunder for deviations in frequency and to play down the unscheduled tie-line control trade between neighboring zones. In control industry, there has been a ceaseless headway within the plan and execution of AGC procedures over a period of more than five decades. It incorporates the application of cutting edge control hypothesis to plan AGC controllers based on ideal, sub-optimal control since of its characteristic merits over classical control hypothesis. Other than, numerous angles like; parameter varieties, versatile and variable structure control, model predictive control (MPC), robust control etc. concepts have been increased with AGC considers. Besides, joining flexible alternating current transmission framework (FACT) gadgets such as high voltage direct current (HVDC) joins, thyristor control phase shifter (TCPS), static synchronous series compensator (SSSC) etc., has been considered in numerous of the ponders. In expansion to this AGC ponders has been seen by integration of wind turbines to cutting edge control framework, consolidation of BESS, SMES and RFB batteries etc. As of late, broad employments of cleverly strategies such as ANN have 
been seen picking up the potential applications within the plan and execution of AGC plans. This method is much valuable in making a difference control engineers to handle the control framework models that are related with non-linearities, unrefined models with lacking data successfully. With expanding complexity of the control framework operation due to integration of modern advances and operational techniques, the plan of AGC has moreover advanced. Amid final six decades broad investigate endeavors have been made within the plan and execution of AGC controllers. These inquire about endeavors driven to the improvement of different control methodologies to plan AGC controllers. The commonly utilized AGC methodologies may be broadly classified into taking after categories:

- AGC schemes based on classical control.

- AGC schemes based on modern control theory.

* Optimal AGC regulator design based on full state vector feedback control.

* Optimal AGC regulator design based on output vector feedback control.

* MPC based AGC regulator design.

- AGC schemes based on adaptive and variable structure control.

- AGC schemes based on robust control techniques.

- AGC schemes based on intelligent techniques.

All of the over methods have their possess points of interest, restrictions and space of applications. A brief writing overview of the existing strategies of AGC and their basic audit are displayed within the taking after area.

\section{CRITICAL AGC ASPECTS}

The AGC is an imperative perspective of control framework operation and control. The complexity of AGC plan depends upon the complexity of the control frameworks and the data accessibility almost the state and annoyances of control frameworks. In later a long time there has been developing intrigued within the integration of wind vitality to the lattice. This has included modern measurement to the AGC issues. The infiltration of wind vitality has persuaded analysts to explore the energetic interest of wind generators in frequency control other than customary generators. Considering this angle, few investigations are accessible within the writing [6-17]. The affect evaluation of high infiltration wind control to the existing control framework is displayed in [6-7].

From the examinations carried out, it can be uncover that in the event that wind turbines can viably take an interest in framework dormancy arrangements, the frequency impact may be altogether relieved. In [8], a strategy based on inertial control, control via power reserve technique and control through communication strategy is displayed on how a variable speed wind turbine can successfully take an interest in frequency control. The concept of discharging the active vitality from a DFIG based wind turbine when the framework frequency is low in arrange to avoid the diminishment of framework inactivity is given in [9]. This strategy proposes the use of an extra control set point within the control framework of the wind turbine and this extra control reference is calculated based on the rate of alter of frequency and dormancy of the organize. The extra control discharged by the DFIG based wind turbine underpins the essential frequency control. The test comes about of DFIG utilizing back-to-back PWM voltage source converters within the rotor circuit are accessible in [10].

In [11], creators propose the two most imperative concept of a variable speed wind turbine in control framework. One is the utilize of a DFIG with a back-to-back voltage source converter bolstering the rotor winding and moment may be a coordinate drive synchronous generator which is associated to the lattice through a diode rectifier and voltage source converter. In [12], wind turbines works concurring to a de loaded ideal control extraction bend such that the dynamic control given by DFIG based wind turbines increments or diminishes amid framework frequency changes. The control methodology is misused through combined control of inactive converters and pitch control, altering the rotor speed and the dynamic control agreeing to the de loaded ideal control extraction bend. In any case, the disadvantage of this strategy is the misfortune of income as the wind generator isn't able to create most extreme control.

In [13], the concept of extricating the dynamic vitality from DFIG based wind turbines which have the substance of imitating inertial control and underpins the essential frequency control is displayed. The energetic cooperation from DFIG in framework frequency control is analyzed by a frequency control back work that reacts relatively to framework frequency deviations and employments the active vitality to make strides the frequency of the framework [14].

The DFIG's commitment in frequency control is examined utilizing representative setting and framework inertial reaction in [15]. In [16], an adjusted inertial control conspire is displayed to have a quick control of framework frequency within the wake of alter in load with successful support from DFIG. In [17], the DFIG based wind turbines are coordinates to a two-area control framework.

\subsection{AGC design based on classical control}


The AGC controllers are planned based on classical control strategy considering especially a particular working condition. Be that as it may, the framework energetic execution corrupts when the working condition changes. The AGC plans based on classical control methods are straightforward to execute and AGC based on these procedures work well in the event that their picks up are ideally decided. Considering this, numerous examinations are detailed within the writing [18-23]. In [18], O. I. Elgerd and C. E. Fosha had decided the ideal integrator picks up for AGC with classical strategy. J. L. Willems [19] has utilized the classical approach to discover the ideal parameters of routine AGC. In [20], Kwatny distinguished a few vital issues related to AGC of control framework. T. Hiyama et al. [21] displayed a strategy to plan discrete time AGC controllers based on routine tie-line inclination control technique for a thermal-thermal control framework with thermal turbines considering framework non-linearity such as GRC. In [22], Kothari et al. have recognized a few viewpoints of examined information AGC based on classical approach. Afterward, the same creators displayed the AGC issue in nonstop and discrete mode utilizing classical approach [23]. The AGC controller plan based on classical control method is restricted to the framework having single input and single yield sort [24]. Be that as it may, the structure of control framework is of multi input and multi yield sort and the controller plan based on classical approach gets to be unsuccessful for such frameworks. The controller based on cutting edge control hypothesis gives arrangements to variable structure control frameworks with different inputs and numerous yields. In such applications, the plan of AGC controller based certain execution record gives palatable execution for the given execution file.

\subsection{AGC schemes based on modern control theory}

The application of present day control hypothesis empowers the plan ideal controllers with regard to a given execution file [25-27]. Elgerd and Fosha were to begin with to display AGC controller plans based on an expected performance index [28]. The control framework demonstrate comprising of indistinguishable thermal control plants having non-reheat turbines are utilized for the studies. In [29], Tacker et al. have examined the energetic execution of a two-area control framework with ideal AGC controllers. K. Yamashita and T. Taniguchi have dissected AGC issue of control frameworks considering from the perspective of ideal control hypothesis [30]. The other calculation was determined by Kothari et al. [31] employing an execution file that circumvents the requirement of a load request estimator. In [32], K. P. S. Parmar et al. have explored the execution of AGC based on full state vector technique for an interconnected control framework with practical limitations. In [33], Ibraheem and P. Kumar have managed a computational approach for the arrangement of the network Riccati condition for ideal full state vector control and after that the weighting frameworks ' $Q$ ' and ' $R$ ' of ideal state control was proposed by Mariano et al. [34]. Afterward, the same creators [35] tended to the stabilization and execution of the AGC controllers by utilizing the ideal control. M. Nakamura and H. Hatazakia [36] have created an ideal AGC for a hydro warm control framework within the summer and stormy season. M. A. Abdel-Halim et al. have planned the ideal AGC controllers for control framework whose dynamical conditions contain a backlash component [37]. Be that as it may, the studies were constrained to single-area control framework as it were. H. G. Kwatny et al. have clarified the ideal AGC definition as a following issue in which vitality source flow and load plays a central part [38]. In [39], A. Kanchanaharuthai proposed an ideal tested information AGC controller plan with time duplicated execution record based on energetic programming. The outlined AGC controller was utilized in arrange to realize not as it were the speedier energetic reaction, such as the incremental frequency deviation, but moreover in expanding the structure of examined information ideal AGC controller from the standard ideal execution list to the case of time duplicated one. Major portion of the investigate work detailed by the engineers/ researchers with respect to the AGC of interconnected control frameworks is restricted either to two-area or multi-area control frameworks considering the framework interconnection by means of A.C. transmission line as it were. As the power requirements are expanding day by day, the engineers within the display circumstances are persuaded to centralize their consideration to produce and transmit gigantic sum of electric control through HVDC transmission framework. The commissioning of a HVDC connect in parallel with existing AC interface to utilize as an range interconnection between two control ranges has progressed the framework soundness to a extraordinary degree [40-42]. In [42], Ibraheem explored the energetic execution of control framework utilizing ideal AGC controllers considering the parallel AC/DC tie-lines. Afterward on, Ibraheem and P. Kumar proposed the ideal AGC controllers plan for a hydro-hydro overwhelming framework with offbeat tie-lines [43-44]. As of late, Ibraheem et al. have proposed the plan of ideal AGC controllers in a deregulated environment with offbeat tie-lines considering distinctive sorts of electric market transactions [45].

From the consider, it is appeared that the outlined AGC controllers have the capability to play down the deviations in frequency and tie-line control trades in a unused control framework environment. Assist, the framework execution gets way better with parallel AC/DC tie-lines as a region interconnection. In all these 
thinks about, the control framework models utilized for examinations were comprising of indistinguishable two-area having non-reheat, reheat-turbines or hydro turbines. An AGC controller for a two-area control framework interconnected by means of nonconcurrent tie-lines with control era through different sources in each zone was proposed in [46]. In [47], an AGC controllers based on ideal control was proposed considering distinctive aspects of controllability and measurability within the plan. In any case, the study is restricted to a control framework demonstrate having two-area as it were. In genuine time working circumstances, the interconnected control frameworks are of multi-area sort and comprising of different sorts of eras through plants of assorted nature. From the writing overview carried out it is watched that most of the thinks about of AGC controllers based on full state vector input control were constrained to indistinguishable two-area control framework models having reheat, non-reheat or hydro turbines and lesser consideration has been paid to AGC of multi-area control framework with control era through plants of different nature in several zones. So also exceptionally few examinations have been done by considering parallel EHVAC/HVDC tie-lines.

\subsection{Optimal AGC design on methodology of output vector feedback control}

The ideal AGC controller plan requires the estimation of all the state factors for criticism. This is often a genuine impediment since of the reality that estimation of all the state factors is restricted in genuine world complex control framework. Beneath such circumstances a few endeavors were made to plan AGC sub-optimal and close ideal control of AGC framework with accessible states [48]. Afterward, the same creators displayed the plan of sub-optimal control for a non-linear control framework [49]. In this way, AGC controller plan utilizing models with diminished orders and neighborhood spectators have been created by A. Feliachi for controlling the plants [50]. The observer based plan of decentralized AGC for control frameworks have been explored in [51]. In [52], Ibraheem et al. displayed and explored the plan of suboptimal AGC controllers which needs as it were effortlessly accessible states for input and contain sufficient data approximately the total framework. The examinations uncover that these controllers have lower framework solidness edges as compared to ideal AGC controllers. Be that as it may, these controllers are taken a toll compelling and they have more noteworthy chance of execution in real world control frameworks. Afterward on the same creators displayed the plan of AGC controllers based on sub-optimal control considering the diverse structures of ' $Q$ ' framework and comes about gotten are compared with that gotten utilizing ideal control [53]. In [54], Kothari et al. displayed the plan of AGC controllers based on effectively accessible yields with differing sources of control era in single range. The outcomes about gotten are very promising. In any case, the thinks about are restricted to single zone control framework as it were. Afterward on the same creators amplified their work on yield vector input control with multi-source control era in each zone of a two-area control framework [55]. E. Rakhshani et al. [56] displayed the decreased order estimator for AGC utilizing linear quadratic regulator (LQR) for the control framework where get to to a few of state factors is constrained and estimation is outlandish. Afterward on E. Rakhshani [57] too displayed the plan of AGC controllers based on yield vector input strategy.

\subsection{MPC based AGC schemes}

MPC is another imperative procedure found to be a proficient control methodology for a number of applications in control industry. It has various focal points such as exceptionally quick reaction, vigor against parameters varieties and load unsettling influences. Its straight forward plan method is one of the major points of interest of this procedure. Be that as it may constrained inquire about endeavors [58-59] were made to investigate this procedure for the plan AGC controllers. T. H. Mohamed et al. presents the application of this procedure to AGC of interconnected control framework [58]. In [59], M. Khalid et al. show the ideal operation of battery vitality capacity framework (BESS) based on MPC procedure in nearness of framework imperatives. Afterward on Mohamed et al. examined the MPC based AGC for an interconnected control framework with and without consolidation of wind turbines. The execution of MPC based AGC controllers was tried against the parameter varieties, load unsettling influences and the results are much way better than customary control procedure [60].

In later a long time the FACTS devices are being coordinates to the control frameworks to realize different destinations. These devices coupled with control gadgets based controllers may too contribute within the advancement of the energetic execution of AGCs. In Most of the AGC thinks about this angle has not been taken into thought. The FACTS such as BESS can successfully soggy out the electromechanical motions of the control framework due to capacity expansion which can share the sudden deficiency within the control prerequisite [61-62]. In [61], creators proposed the BESS to progress the AGC elements of West Berlin Electric Supply Framework. In [62], S. K. Aditya and D. Das explored the positive impact of BESS for AGC of control framework. From the examinations carried out it was uncovered that BESS is supportive in assembly a sudden alter in load request of framework and can successfully diminish the frequency and tieline control deviations. However, the problem of low discharge rate, increased time requirement for power 
flow reversal have led to advancement of superconducting magnetic energy storage (SMES) as compelling stabilizer in control framework [63-67]. S. C. Tripathy et al. explore the execution of adaptive controlled SMES as compared to non-adaptive SMES and it has been watched that when SMES control is adaptive, the execution of the framework is uncaring to parameter varieties [63]. Afterward on the same creators examined the impact of SMES on AGC considering the framework non-linearities such as dead-band of governor, limitation of reheat and boiler dynamics [64]. In [65], S. C. Tripathy et al. explore the AGC execution in tested information mode with SMES. R. Abraham et al. [66] examine the AGC issue of a hydro-thermal control framework with consolidation of SMES units.

From the examinations carried out, it can be uncover that SMES unit fitted in both the regions progresses the energetic execution of the framework taking after a load unsettling influence in either of the ranges. In any case, the SMES impact is restricted to the region in which it is found and has nearly no back to support control of other regions. Within the setting of advanced control frameworks with competitive trade environment, the slant is to move forward the control exchange capability of existing transmission lines. The later advancement of FACTS such as TCPS, SSSC, inactive VAR compensation etc., have made it conceivable to exchange more control through existing lines as compared to developing unused ones. These devices are effectively connected in control framework to make strides the relentless state and energetic execution and to fine control the stream of control in either headings [68-72]. In [69], P. Bhatt et al. explored the impact of thyristor control phase shifter (TCPS) and SMES in AGC thinks about. Afterward P. Bhatt et al. [70] explored the AGC issue of multi-unit all hydro framework and illustrated that frequency is profoundly touchy to load irritation and framework gets to be unsteady indeed for a sudden load annoyance due to higher reaction times related with hydro generators. Be that as it may, when a TCPS is introduced in arrangement with the tie-line in coordination with SMES units introduced in each region of hydro ruling control framework, the energetic execution of AGC controller is significantly progressed. The same creators moreover explored the energetic execution of diverse control framework models in coordination control of TCPS and SMES [71]. The SMES innovation is exceptionally costly and has operational issues due to complex equipment and so more reasonable lossy magnetic energy storage framework (LMES) can be a successful elective. LMES is conservative, upkeep free, solid and long-lasting [73]. S. C. Tripathy proposes the capacitive energy storage (CES) framework for AGC issue of an interconnected control framework [74]. The thought behind the examination was that, a little rating CES unit can viably soggy the deviations and is less expensive and less misfortunes as compared to SMES and LMES units. S. Jalilzadeh et al. [75] displayed the comparative execution of CES and SSSC considering different setups for AGC issue of multi-unit control framework. From the examination carried out it was concluded that the combination of AGC and CES is predominant as compared to other arrangements in terms of slightest overshoot and settling time. As of late, I. A. Chidambaram et al. explored the coordination control of redox flow battery (RFB) and interline power flow controller (IPFC) in AGC. The investigations uncover that the energetic execution of control framework moves forward to an extraordinary degree by appropriate putting of RFB and IPFC in arrangement with the transmission line [76].

From the over writing study, it has been watched that most of the thinks about were constrained to indistinguishable two-area or multi-area control framework models having reheat or non-reheat turbines and lesser consideration have been paid to AGC of control framework having hydro turbines which have broadly distinctive characteristics from thermal turbines. FACTS have the capability to move forward the execution of such control framework models within the wake of alter in load request. Considering this, exceptionally few investigations are accessible within the writing and it needs advance change. On the other side, the AGC controller plan based on full state vector input control requires all the state factors for criticism. Be that as it may, it is incomprehensible to have all the state factors open and quantifiable in genuine control frameworks. This issue can be overcome by output vector feedback control, which needs as it were effectively accessible yields for criticism. Besides, small consideration has been paid to plan AGC controllers based on output vector feedback control for a multi-area control framework with control era through plants of differing nature associated through EHVAC as well as HVDC tie-lines and exceptionally few endeavors have been made in AGC thinks about to plan AGC controllers for a hydro-thermal control framework interconnected by means of parallel EHVAC/HVDC tie-lines with viable cooperation from DFIG based wind turbines in conjunction with ordinary generators. On the other side, MPC shows up to be exceptionally successful and productive control procedure for a number of applications in different businesses. Its straight forward plan is one of the greatest preferences of this method. The imperatives can be forced on inputs as well as yields which makes it a proficient control procedure for AGC. From the accessible writing, it has been watched that exceptionally small consideration have been paid to plan AGC controllers utilizing MPC method with energetic cooperation from DFIG based wind turbines with facilitated operation of Realities. Encourage, in most of the thinks about proposed so distant for AGC, the AGC controller execution is decided on step load unsettling influence strategy. In any case, this strategy does not legitimize the application of AGC controllers for real 
control frameworks. In commonsense control frameworks, the load changes concurring to customers' load request. Subsequently, plan of AGC ought to take under consideration the variety of load by short term load forecasting (STLF) [77-81]. Considering all these issues, the MPC based AGC controller plan needs advance examinations for a two-area control framework with energetic support from DFIG based wind turbines in coordination control of Truths and for a multi-area control framework interconnected by means of offbeat tielines utilizing STLF.

\subsection{AGC schemes based on adaptive and variable structure design}

The AGC controller plans for control framework talked about over are based on ostensible framework parameters. The values of the framework parameters alter due to natural impacts, maturing of framework components and changes within the working conditions of the framework. Subsequently, the AGC controller plan based on genuine framework parameters may not be truly ideal in case of parameter varieties and vulnerabilities. This may comes about in weakening of energetic execution of control framework and may misfortune the framework soundness. To overcome this, a few creators have proposed versatile and variable structure based AGC controller plan [82-91]. Pan et al. proposed a versatile control procedure to meet the hyper soundness condition prerequisites considering plant parameter varieties [82]. In [83], creators proposed versatile control methodology for a multi-area control framework. Diminished arrange versatile AGC controller plan for interconnected control framework is additionally accessible within the literature [84]. A self-tuning calculation for AGC to supply promising execution for a wide run of working conditions was detailed by Lee et al. [85]. In [86], Talaq and Al-Basri proposed a versatile pick up planning approach for AGC issue of interconnected control framework. The results about gotten are very promising by these sorts of versatile controllers. In any case, these calculations are complex and require online recognizable proof of framework demonstrate. A few creators connected the concept of variable structure control strategy to plan AGC controllers [87-90]. In [91] moreover, Q. P. Ha et al. proposed a variable structure based AGC controller plan for electric control system. This approach combines the concept of variable structure and fuzzy tuning to realize tall level of execution and vigor. The AGC outcomes are very promising. In any case, the complexity of variable structure control method and related chattering issue may be the reason that these controllers are not effectively executed in AGC applications.

\subsection{AGC schemes on robust control design}

In genuine time applications of control framework, distinctive zones contain distinctive sorts of vulnerabilities and unsettling influences due to changes in framework characteristics, parameter varieties, load changes, blunder in modeling and linearization. Hence, a few creators proposed the plan of AGC controllers utilizing strong control methods [92-98] to overcome these issues and to supply a more successful arrangement for AGC. In [92], Wang et al. proposed the strong control plan based on Riccati condition approach for AGC of control framework to bargain with the framework instabilities in a more productive way. In [93], A. M. Stankovi et al. proposed a vigorous control plan based on quantitative input hypothesis which offers a deliberate environment for plan and investigation considering physical understanding of the control framework. Afterward on a vigorous control plan utilizing $\mathrm{H} \infty$ control method joining framework parameter varieties was proposed by M. Karrari et al [94]. The outlined controller is fruitful in giving great execution for all permissible plant parametric vulnerabilities. In [95], Azzam proposed a vigorous controller plan based on closed-loop eigenvalues which have least affectability to plant parametric varieties. In [96], Shayeghi et al. created strong controller based on $\mu$-synthesis and examination procedure considering plant parametric vulnerabilities and outcomes are compared with ordinary PI controller for a wide extend of parametric varieties in nearness of GRC. In [97], Azzam and Mohammed proposed a strong control plan based on Q-parameterization hypothesis. All over vigorous control methods appear great energetic execution for all plant parametric changes. Be that as it may, most of these methods were based on state criticism strategy and it is truly troublesome to have all the state factors accessible for input in genuine circumstances and troublesome to realize them in down to earth control framework.

\subsection{AGC schemes depend on intelligent techniques}

For the most part, in AGC considers the non-linear plants are approximated by decreased arrange direct models of control framework. These models are substantial inside certain particular working conditions and a distinctive show may be required as before long as the working condition changes. In later a long time the application of ANNs has been explored within the design of AGC controllers to manage up with changing working situation and nonlinearities of the control frameworks [99-113]. B. Franoise et al. proposed multi-layer perceptron (MLP) neural systems for AGC of control framework prepared through back back propagation through time algorithm [99]. The results are very promising. In [100], Douglas et al. displayed a self organizing Kohonen ANN to classify the unsettling influence into long term and brief term 
one and thus, choose whether AGC will be enacted or not. In [101], Chaturvedi et al. illuminated the AGC issue by utilizing the generalized neural network approach to abdicate superior framework temporal execution as compared to conventional ANN. In [102], Ahamed et al. proposed the reinforcement learning algorithms for finding the ideal arrangement of an AGC issue. Afterward the same calculation is utilized in [103] with GRC. In [104], the same creators made strides the energetic execution of control framework employing a radial basis function (RBF) networks trained through reinforcement learning. In [105], both $\mathrm{RBF}$ and hybrid fuzzy neural systems are utilized where the framework is linearized around an working point to demonstrate the non-linear control framework. In [106], Demiroren et al. displayed the MLP neural systems based AGC of an interconnected control framework in nearness of dead-band and GRC. Be that as it may, the outcomes are constrained to two range control frameworks as it were. Afterward on the same creator amplified their work to multi-area control framework [107]. In [108], the same creator joined the SMES in control framework show to move forward the framework execution with ANN controller. As of late, the strong control approach are utilized by a few of the analysts to prepare the ANN based AGC controllers [109-110]. Shayeghi et al. displayed the thought of $\mathrm{H} \infty$ procedure to prepare the spiral premise work neural systems beneath different working conditions [109]. In [110], the same creator consolidate the plan of $\mu$-synthesis for preparing of MLP neural systems for AGC of control framework to attain improved level of strong execution for all permissible vulnerabilities beneath wide run of working conditions. In [111], Saikia et al. have examined reinforced learning ANN based AGC controllers for a multi-area hydro-thermal control framework. A comparative think about of versatile controllers based on energetic neural systems was proposed by Oysal [112]. Be that as it may, the ANN design utilized in most of these thinks about are MLP neural systems in which there's no criticism from the yield of one layer to the input of prior layers of neurons. These systems have no memory, as the yield at any moment depend completely on the inputs and the weight at that moment. Assist changes can be achieved by employing a course of neural organize which has memory such as repetitive neural systems. These sorts of systems have at slightest one criticism association from the yield of a layer to its input so that enactment work can stream in a closed circle in this way shaping a repetitive association. The criticism is postponed in time so that organize can store its past behavior. These systems show characteristics comparative to short-term memory, as the yield of the system depends on both the current and earlier inputs [113]. In recurrent ANN the data approximately the past behavior of the framework gives an interesting depiction of its future behavior. Hence recurrent ANN systems can be successfully utilized in AGC controller plan.

Support Vector Machines (SVMs) is another lesson of machine learning methods which has great work estimation and classification capabilities [114]. SVMs have way better generalization capability than the customary neural systems. The SVM can perform nonlinear classification errand by employing a bit. The part maps the non-linearly divisible information to straightly divisible information into a high dimensional highlight space. Analysts have utilized the SVMs in numerous applications such as movement control of robot [115] and stator blame determination for induction engines [116]. The initial SVMs requires fathoming quadratic programming which needs long time computation and needs amazingly huge memory. To unravel this disadvantage, different strategies are proposed such as least squares support vector machine (LS-SVM) [117] and midpoint approval strategy for SVMs [118]. Among them, LS-SVM develops as an effective computational strategy. The LS-SVMs is prevalent to conventional SVMs in terms of basic calculation, great exactness and quick merging [119-120]. An application of LS-SVM to ideal control of non-linear framework is given in [121].

From the writing study carried out, it has been watched that the AGC controllers plan based on ideal and sub-optimal control works exceptionally well on genuine framework parameters and fizzled to supply the required energetic execution for framework parametric varieties. Considering this issue, a few creators have proposed the AGC controller plan based on strong control procedures, which guarantee the generally solidness of the framework for wide run of parameter varieties. Be that as it may, these controllers were fixed, based on state criticism strategy and fizzled to supply the required framework energetic performance for a wide extend of working conditions. To overcome these disadvantages, application of ANNs has been explored within the plan of AGC. The ANN has the capability to plan AGC controllers which can work viably for inconspicuous information and for all permissible parametric instabilities beneath differing working conditions. Be that as it may, the foremost of the considers proposed so distant for AGC were based on MLP ANN and no consideration has been paid to plan AGC controllers based on recurrent ANN engineering for AGC of an interconnected control framework.

The recurrent ANN systems appear to have more potential than MLP due to its past behavior capacity capability which is exceptionally valuable in predicting future behavior. Within the writing the potential of recurrent ANN organize has not been abused for AGC application. The SVMs is another lesson of machine learning strategies which has risen as an effective strategy with great work guess and classification capabilities. Among different variations of SVMs, the LS-SVM is prevalent to conventional 
SVMs in terms of straightforward calculation, tall accuracy and quick joining [119-120]. The LS-SVM has the capability to plan non-linear AGC controllers for cutting edge control frameworks which are non-linear, huge, and complex.

\section{CONCLUSIONS}

On the premise of basic survey carried out within the field of cutting edge electric vitality framework i.e. AGC; the taking after conclusions are drawn:

It is watched that most of the ponders of AGC controllers based on full state vector feedback control were constrained to indistinguishable two-area control framework models having reheat, non-reheat or hydro turbines and lesser consideration has been paid to AGC of multi-area control framework with control era through plants of different sorts completely different zones. So also exceptionally few examinations have been done by considering parallel AC-DC tie-lines.

From the survey, it is additionally watched that lesser consideration has been paid to plan AGC controllers based on output vector feedback control strategy for control framework which are hydro overwhelming and have FACTS associated to progress system performance. Encourage, it is additionally found that small consideration has been paid to plan AGC controllers for a multi-area control framework with control era through plants of different sorts associated through EHVAC as well as HVDC tie-lines and exceptionally few endeavors have been made in AGC ponders to plan AGC controllers for a hydro-thermal control framework interconnected by means of parallel EHVAC/HVDC tie-lines with compelling support from DFIG wind era.

Advance, the MPC based AGC controller plan needs advance examinations for present day control framework with energetic interest from DFIG based wind turbines in coordination control of actualities and for a multi-area control framework interconnected by means of offbeat tie-lines. Besides to create the AGC valuable for viable control framework the plan of AGC ought to moreover explore the variety of load by STLF.

It is additionally found that ANN based AGC have the capability to handle differing working conditions and non-linearity of control frameworks in an improve way. In any case existing ANN (MLP) based strategies requires appropriate choice of covered up layer, number of neurons per covered up layer and thorough information set for preparing. The recurrent ANN have much way better generalization capability than MLP and can be successfully utilized in AGC controller plan.

LS-SVM is course of machine learning procedures which has fabulous work guess and classification capabilities. The LS-SVM has been effectively utilized within the plan of ideal controller for the non-linear control framework. In any case, its pertinence for the plan of AGC may demonstrate to be a compelling plan procedure for cutting edge and complex control framework having control era through discontinuous renewable innovations.

\section{REFERENCES}

[1] L. K. Kirchmayer, Economic Control of Interconnected Systems. New York: Wiley, 1959.

[2] D. P. Kothari and I. J. Nagrath, Modern Power System Analysis. New Delhi: Tata McGraw-Hill, 2003.

[3] A. J. Wood and B. F. Wollenberg, Power Generation Operation and Control. New York: John Wiley and Sons, 1996.

[4] N. V. Ramana, Power System Operation and Control. South Asia: Pearson, 2012.

[5] S. Sivanagaraju and G. Sreenivasan, Power System Operation and Control. India: Pearson, 2012.

[6] P. Keung, P. Lei, H. Banakar, and B. T. Ooi, "Kinetic energy of wind-turbine generators for system frequency support," IEEE Trans. Power Syst., vol. 24, no. 1, pp. 279-287, Feb. 2009.

[7] G. Lalor, J. Ritche, S. Rourke, D. Flynn, and M. J. O' Malley, "Dynamic frequency control with increasing wind generation," Proceedings of the IEEE Power Engineering Society General Meeting, Denver, CO, 6-10 June 2004.

[8] X. Yingcheng, and T. Nengling, "Review of contribution to frequency control through variable speed wind turbine," Renew. Energy, vol. 36, no. 6, pp. 1671-1677, 2011.

[9] J. Ekanayake, and N. Jenkins, "Comparison of the response of doubly fed and fixed-speed induction generator wind turbines to change in network frequency," IEEE Trans. Energy Conversion, vol. 19, no. 4, pp. 800-802, Dec. 2004.

[10] R. Pena, and J. C. Clare, "Doubly fed induction generator using back-to-back PWM converters and its application to variable speed wind-energy generation," Power Appl., vol. 143, no. 3, May 1996.

[11] J. G. Slootweg, S. W. H. de Haan, H. Polinder, and W. L. Kling, "General Model for representing variable speed wind turbines in power system dynamics simulations," IEEE Trans. Power Syst., vol. 18, no. 1, Feb. 2003.

[12] R. G. De Almeida, and J. A. P. Lopes, "Participation of doubly fed induction wind generators in system frequency regulation," IEEE Trans. Power Syst., vol. 22, no. 3, pp. 944-950, Aug. 2007.

[13] J. Morren, S. W. H. Haan, W. H. Kling, and J. A. Ferreira, "Wind turbines emulating inertia and supporting primary frequency control,” IEEE Trans. Power Syst., vol. 21, no. 1, pp. 433-434, Feb. 2006. 
[14] P. Bhatt, R. Roy, and S. P. Ghoshal, "Load frequency control of interconnected restructured power system along with DFIG and coordinated operation of TCPS-SMES,"11th International Conference on Probabilistic Methods Applied to Power Systems (PMAPS 2010), pp. 131-136, Singapore, 14-17 Jun. 2010.

[15] M. Kayikci, and J. V. Milanovic, "Dynamic contribution of DFIG-based wind plants to system frequency disturbances," IEEE Trans. Power Syst., vol. 24, no. 2, pp. 859-867, May 2009.

[16] J. M. Mauricio, A. Marano, A. Gomez-Exposito, and J. L. M. Ramos, "Frequency regulation contribution through variable-speed wind energy conversion systems," IEEE Trans. Power Syst., vol. 24, no. 1, pp. 173-180, Feb. 2009.

[17] M. Jalali, "DFIG based wind turbine contribution to system frequency control", Ph.D. Thesis, University of Waterloo, Canada, 2011.

[18] O. I. Elgerd, and C. E. Fosha, "Optimum megawatt frequency control of multi-area electric energy systems," IEEE Trans. Power Apparat. Syst., vol. 89, no. 4, pp. 556-563, April 1970.

[19] J. L. Willems, "Sensitivity analysis of the optimum performance of conventional load frequency control," IEEE Trans. Power Apparat. Syst., vol. 93, no. 5, pp. 1287-1291, Sept. /Oct. 1974.

[20] H. G. Kwatny, and T. A. Athay, "Coordination of economic dispatch and load frequency control in electric power systems," Proceedings, 18th IEEE Conference on Decision and Control, 1979.

[21] T. Hiyama, "Optimization of discrete-type load-frequency regulators considering generation rate constraints," Proc. IEE, vol. 129, no. 6, pp. 285-289, Nov. 1982.

[22] M. L. Kothari, P. S. Satsangi, and J. Nanda, "Sampled data automatic control of interconnected reheat thermal stations consisting generation rate constraints," IEEE Trans. Power Apparat. Syst., vol. 100, no. 5, pp. 2334-2342, May 1981.

[23] M. L. Kothari, P. S. Satsangi, and J. Nanda, "Automatic generation control of an interconnected hydrothermal system in continuous and discrete mode considering generation rate constraints," Proc. IEE, vol. 130, no.1, pp. 1727,1983

[24] Ibraheem, P. Kumar, and D. P. Kothari, "Recent philosophies of automatic generation control strategies in power systems," IEEE Trans. Power Syst., vol. 20, no. 1, pp. 346-57, Feb. 2005.

[25] M. Athans, and P. Falb, "The design of optimal linear system with quadratic criteria," in Optimal Control: An Introduction to the Theory and Its Application, New York: McGraw-Hill, pp. 750-771, 1966.

[26] B. D. O. Anderson, and J. B. Moore, "The standard regulator problem-II," in Optimal Control: Linear Quadratic Methods, Prentice Hall, pp. 35-51, 1989.

[27] F. Llewis, and V. L. Syrmos, Optimal control, New Jersy, Englewood Cliffs: Prentice Hall, 1995.

[28] C. E. Fosha, and O. I. Elgerd, "The megawatt frequency control problem: A new approach via optimal control theory," IEEE Trans. Power Apparat. Syst., vol. 89, no. 4, pp. 563-577, April 1970.

[29] E. C. Tacker, C. C. Lee, T. W. Reddoch, T. O. Tan, and P. M. Julich, "Optimal control of interconnected electric energy systems-A new formulation,” Proceedings of IEEE, vol. 60, no. 10, pp. 1239-1241, Oct. 1972.

[30] K. Yamashita and T. Taniguchi, "Optimal observer design for load frequency control,” Int. J. Electr. Power Energy Syst., vol. 8, no. 2, pp. 93-100, April 1986.

[31] M. L. Kothari and J. Nanda, "Application of optimal control strategy to automatic generation control of a hydrothermal system," IEE Proceedings-D, vol. 135, no. 4, pp. 268-274, July1988.

[32] K. P. S. Parmar, S. Majhi and D. P. Kothari, "Optimal load frequency control of an interconnected power system," Int. J. Electr. Instrumentation Engg., vol. 1, no. 1, pp. 1-5, Jan. 2011.

[33] Ibraheem and P. Kumar, "A novel approach to the matrix Riccati equation solution: an application to optimal control of interconnected power systems," Electric Power Comp. Syst., vol. 32, no. 1, pp. 33-52, 2004.

[34] S. J. P. S. Mariano, J. A. N. Pombo, M. R. A. Calado and L. A. F. M. Ferreira, "Optimal output control: load frequency control of a large power system," International Conference on Power Engineering, Energy and Electrical Drives, Lisbon, pp. 369-374, March 18-20, 2009.

[35] S. J. P. S. Mariano, J. A. N. Pombo, M. R. A. Calado and L. A. F. M. Ferreira, "A procedure to specify the weighting matrices for an optimal load frequency controller," Turkish Journal of Electrical Engineering and Computer Sciences, vol. 20, no. 2, pp. 1-13, 2012.

[36] M. Nakamura and H. Hatazakia, "New load frequency control system based on optimal control theory," Electrical Engineering in Japan, vol. 97, no. 4, 1977.

[37] M. A. Abdel-Halim, G. S. Chritensen and D. H. Kelly, "Optimal load frequency control with governor backlash," Journal of Optimization Theory and Applications, vol. 45, no. 4, pp. 505-516, April 1985.

[38] H. G. Kwatny, K. C. Kalnitsky and A. Bhatt, "An optimal tracking approach to load frequency control," IEEE Trans. Power Apparat. Syst., vol. 94, no. 5, pp. 1635-1643, September 1975.

[39] A. Kanchanaharuthai, "Optimal sampled-data controller design with time-multiplied performance index for load frequency control," Proceedings of the IEEE Conference on Control Applications, Taiwan, vol. 1, pp. 655-660 , Sept. 2-4, 2004.

[40] Y. Yoshida, T. Machida and N. G. Hingorani, "Analog computer study of automatic frequency ratio control on an HVDC transmission system,” IEEE Trans. Power App. Syst.,vol. 87, no. 3, pp. 796-807, March 1968.

[41] M. Sanpei, A. Kakehi and H. Takeda, "Application of multi-variable control for automatic frequency controller of HVDC transmission system,” IEEE Trans. Power Delivery, vol. 9, no. 2, pp. 1063-1068, April 1994.

[42] Ibraheem, Optimal control strategies in interconnected power systems incorporating AC/HVDC transmission links, Ph.D. Thesis, Deptt. of Electrical Engg., AMU, Aligarh, India, 2001.

[43] P. Kumar and Ibraheem, "Current status of the Indian power system and dynamic performance enhancement of hydro power systems with asynchronous tie-lines," Electric Power Comp. Syst., vol. 31, no. 7, pp. 605-626, 2003. 
[44] P. Kumar and Ibraheem, "Dynamic performance enhancement of hydro power system with asynchronous tie-lines," J. Institution of Engineers (IEI), vol. 85, pp. 23-34, 2004.

[45] Ibraheem, P. Kumar, N. Hasan, and Y. Singh, "Optimal automatic generation control of interconnected power system with asynchronous tie-lines under deregulated environment," Electric Power Comp. Syst., vol. 40, no. 10, pp. 1208-1228, 2012.

[46] Ibraheem, Nizamuddin, and T. S. Bhatti, "AGC of two area power system interconnected by AC/DC links with diverse sources in each area,” Int. J. Electr. Power Energy Systs., vol. 55, pp. 297-304, 2014.

[47] N. Hasan, Ibraheem, and P. Kumar, "Optimal automatic generation control of interconnected power system considering new structures of matrix Q," Electric Power Comp. Syst., vol. 41, no. 2, pp. 136-156, 2013.

[48] V. R. Moorthi and R. P. Aggarawal, "Suboptimal and near optimal control of a load frequency control system," Proceedings of the Institution of Electrical Engineers, vol. 119, no.11, pp. 1653-1660, Nov. 1972.

[49] V. R. Moorthi and R. P. Aggarwal, "Suboptimal regulation of nonlinear load frequency control systems," Proceedings of the IEEE Conference, C-73, pp. 099-9, 1973.

[50] A. Feliachi, "Load frequency control using reduced order models and local observers," Int. Journal of Energy Systs., vol. 7, no. 2, pp. 72-75, 1987.

[51] S. Velusami and K. Ramar, "Design of observer-based decentralized load-frequency controllers for interconnected power systems," Int. Journal of Power Energy Syst.,vol. 17, no. 2, pp. 152-160, 1997.

[52] Ibraheem, P. Kumar, N. Hasan, and Nizamuddin, "Sub-optimal automatic generation control of interconnected power system using output vector feedback control strategy," Electric Power Comp. Syst., vol. 40, no. 9, pp. 977 994, 2012.

[53] N. Hasan, Ibraheem, and P. Kumar, "Sub-optimal automatic generation control of interconnected power system using constrained feedback control strategy," Int. J. Electr. Power Energy Syst., vol. 43, no. 1, pp. 295-303, 2012.

[54] K. P. S. Parmar, S. Majhi, and D. P. Kothari, "Load frequency control of a realistic power system with multi-source power generation," Int. J. Electr. Power Energy Syst., vol. 42, no.1, pp. 426-433, 2012.

[55] K. P. S. Parmar, S. Majhi, and D. P. Kothari, "Load frequency control of an interconnected power system with multi-source power generation in deregulated power environment," Int. J. Electr. Power Energy Syst., vol. 57, pp. 277-286, 2014.

[56] E. Rakhshani and J. Sadeh, "A reduced order estimator with prescribed degree of stability for two area LFC system in a deregulated environment," IEEE Conference and Exposition (PSCE-2009), pp. 1-8, Seattle, WA, 15-18 March 2009.

[57] E. Rakhshani, "Intelligent linear quadratic optimal output feedback regulator for deregulated automatic generation control system," Electric Power Comp. Syst., vol. 40, no. 5, pp. 513-533, 2012.

[58] T. H. Mohamed, H. Bevrani, A. A. Hassan, and T. Hiyama, "Decentralized model predictive based load frequency control in an interconnected power system," Energy Conv. Manag., vol. 52, no. 2, pp. 1208-1214, 2011.

[59] M. Khalid, and A. V. Savkin, "An optimal operation of wind energy storage system for frequency control based on model predictive control," Renew. Energy, vol. 48, pp. 127-132, 2012.

[60] T. H. Mohamed, J. Morel, H. Bevrani, and T. Hiyama, "Model predictive based load frequency control design concerning wind turbines,” Int. J. Electr. Power Energy Syst., vol.43, pp. 859-867, 2012.

[61] H. J. Kunish, K. G. Kramer, and H. Domnik, "Battery energy storage another option for load frequency control and instantaneous reserve," IEEE Trans. Energy Conv., vol. 1, no. 1, pp. 46-51, 1986.

[62] S. K. Aditya and D. Das, "Battery energy storage for load frequency control of an interconnected power system," Elect. Power Syst. Res., vol. 58, no. 3, pp. 179-185, Jul. 2001.

[63] S. C. Tripathy, R. Balasubramanian and P. S. C. Nair, "Adaptive automatic generation control with superconducting magnetic energy storage in power system,” IEEE Trans. Energy Convers., vol. 7, no. 3, pp. 434441, Sept. 1992.

[64] S. C. Tripathy, R. Balasubramanian and P. S. C. Nair, "Effects of superconducting magnetic energy storage on automatic generation control considering governor dead-band and boiler dynamics," IEEE Trans. Power Syst., vol. 7, no. 3, pp. 1266-1273, Aug. 1992.

[65] S. C. Tripathy and K. P. Juengst, "Sampled data automatic generation control with superconducting magnetic energy storage in power systems," IEEE Trans. Energy Convers., vol. 12, no. 2, pp. 187-192, Jun. 1997.

[66] R. J. Abraham, D. Das and A. Patra, "Automatic generation control of an interconnected hydro thermal power system considering superconducting magnetic energy storage,” Int. J. Electr. Power Energy Syst., vol. 29, no. 8, pp. 571-579, 2007.

[67] A. Demiroren, and E. Yesil, "Automatic generation control with fuzzy logic controllers in the power system including SMES units,” Int. J. Electr. Power Energy Syst., vol. 26, no. 4, pp. 291-305, 2004.

[68] P. Kundur, Power System Stability and Control. New York: McGraw-Hill, 1994.

[69] P. Bhatt, S. P. Ghoshal and R. Roy, "Coordinated control of TCPS and SMES for frequency regulation of interconnected restructured power systems with dynamic participation from DFIG based wind farm," Renew. Energy, vol. 40, pp. 40-50, 2012.

[70] P. Bhatt, R. Roy and S. P. Ghoshal, "Comparative performance evaluation of SMES-SMES, TCPS-SMES and SSSC-SMES controllers in automatic generation control for a two area hydro-hydro system," Int. J. Electr. Power Energy Syst., vol. 33, no. 10, pp. 1585-1597, 2011.

[71] P. Bhatt, S. P. Ghoshal and R. Roy, "Load frequency stabilization by coordinated control of thyristor controlled phase shifters and superconducting magnetic energy storage for three types of interconnected two-area power systems,” Int. J. Electr. Power Energy Syst., vol. 32, no. 10, pp. 1111-1124, 2010. 
[72] P. Bhatt, R. Roy and S. P. Ghoshal, "Optimized automatic generation control by SSSC and TCPS in coordination with SMES for two area hydro-hydro power system," IEEE Conference on Advances in Computing Control and Telecommunication Technologies, pp. 474-480, 2009.

[73] S. C. Tripathy, S. Bandopadhyay and J. K. Chatterjee, "Lossy magnetic energy storage units for improvement in automatic generation control," Int. J. Electr. Power Energy Syst., vol. 11, no. 4, pp. 284-252, 1987

[74] S. C. Tripathy, "Improved load frequency control with capacitive energy storage," Energy Conv. Manag., vol. 38, no. 6, pp. 551-562, 1997

[75] S. Jalilzadeh, J. Gholinezhad and P. Farhang, "Load frequency stabilization in two area interconnected system using CES and SSSC," ICACSIS 2011, pp. 37-42, 2011.

[76] I. A. Chidambaram, and B. Paramasivam, "Optimized load-frequency simulation in restructured power system with redox flow batteries and interline power flow controller," Int. J. Electr. Power Energy Syst.,vol. 50, pp. 9-24, 2013.

[77] W. Charytoniuk, and M. Chen, "Very short-term load forecasting using artificial neural networks," IEEE Trans. Power Systems, vol. 15, no. 1, pp. 263-268, Feb. 2000.

[78] D. J. Trudnowski, W. L. McReynolds, and J. M. Johnson, "Real-time very short-term load prediction for power system automatic generation control," IEEE Trans. Control Systems Technology, vol. 9, no. 2, pp. 254-260, March 2001.

[79] P. Shamsollahi, K. W. Cheung, Q. Chen, and E. H. Germain, "A neural network based very short term load forecaster for the interim ISO New England electricity market system," Power Industry Computer Applications, pp. 217-222, May 2001

[80] L. S. Ribeiro Neto, K. Figueiredo, M. Vellasco, and M. A. Pacheco, "Modeling neural nets to very short-term load forecasting," 7thSymposium of Specialists in Electric Operational and Expansion, Curitiba, Aceito, 2000.

[81] K. Shankar, K. Chatterjee, T. K. Chatterjee, "A very short-term load forecasting using Kalman filter for load frequency control with economic load dispatch,” Journal of Engg. Science Tech and Rev., vol. 5, no. 1, pp. 97-103, 2012.

[82] C. T. Pan, and C. M. Liaw, "An adaptive controller for power system and load frequency control," IEEE Trans Power Syst., vol. 4, no. 1, pp. 122-128, 1989.

[83] R. R. Shoults, and J. A. J. Ibarra, "Multi-area adaptive LFC developed for a comprehensive AGC simulator," IEEE Trans. Power Syst., vol. 8, no. 2, pp. 541-547, 1993.

[84] C. M. Liaw, "Design of a reduced-order adaptive LFC for an interconnected hydrothermal power system," Int. J. Control, vol. 60, no. 6, pp. 1051-1063, 1994.

[85] K. A. Lee, H. Yee, and C. Y. Teo, "Self-tuning algorithm for automatic generation control in an interconnected power system," Elect. Power Syst. Res., vol. 20, no. 2, pp. 157-165, 1991.

[86] J. Talaq, and F. Al-Basri, "Adaptive fuzzy gain scheduling for load-frequency control," IEEE Trans Power Syst., vol. 14, no. 1, pp. 145-150, 1999.

[87] A.Y. Sivaramkrishna, M. V. Hariharan, and M. C. Srisailam, "Design of variable structure load frequency controller using pole assignment technique," Int. J. Control, vol. 40, no. 3, pp. 487-498, 1984.

[88] A. Kumar, O. P. Malik, and G. S. Hope, "Variable-structure-system control applied to AGC of an interconnected power system,” IEE Proc. Gen. Transm. Distrib., vol. 132, no. 1, pp. 23-29, 1985.

[89] A. Kumar, O. P. Malik, and G. S. Hope, "Discrete variable-structure controller for load frequency control of multiarea interconnected power system," IEE Proc. Gen. Transm. Distrib., vol. 134, no. 2, pp. 116-122, 1987.

[90] D. Das, M. L. Kothari, D. P. Kothari, and J. Nanda, "Variable structure control strategy to automatic generation control of interconnected reheat thermal systems," IEE Proc. Contr. Theor. Appl., vol. 138, no. 6, pp. 579-585, 1991.

[91] Q. P. Ha, and H. Trinh, "A variable-structure based controller with fuzzy tuning for load frequency control,” Int. J. Power Energy Syst., Vol. 0, no. 0, pp. 1-17, 2001.

[92] Y. Wang, R. Zhou, and C. Wen, "Robust load-frequency controller design for power systems," IEE Proc. Gen. Transm. Distrib., vol. 140, no. 1, pp. 111-116, 1993.

[93] A. M. Stankovi, G. Tadmor, and T. A. Sakharuk, "On robust control analysis and design for load frequency regulation,” IEEE Trans Power Syst., vol. 13, no. 2, pp. 449-454, 1998.

[94] M. Karrari, H. Shayeghi, M. Abedi, and M. B. Menhaj, "Design of Ho controller load frequency control in electrical power systems," Amirkabir J. Sci. Technol., vol. 11, no. 41, pp. 79-88, 1999.

[95] M. Azzam, "Robust automatic generation control," Energy Conv. Manag., vol. 40, no. 13, pp. 1413-1421, 1999.

[96] H. Shayeghi, M. Karrari, and M. B. Menhaj, "Theory of $\mu$-synthesis for power systems load frequency control," J. Electron. Eng., vol. 51, pp. 258-263, 2000.

[97] M. Azzam, and Y. S. Mohamed, "Robust controller design for automatic generation control based on Qparameterization,” Energy Conv. Manag., vol. 43, no. 13, pp. 1663-1673, 2002.

[98] H. Bevrani, Robust Power System Frequency Control. Springer International Publishers, New York: 2009.

[99] B. Franoise, Y. Magid, and W. Bernard, "Application of neural networks to load-frequency control in power systems," Neural Networks, vol. 7, no. 1, pp. 183-194, 1994.

[100] L. D. Douglas, T. A. Green, and R. A. Kramer, "New approaches to the AGC nonconforming load problem," IEEE Trans Power Syst., vol. 9, no. 2, pp. 619-628, 1994

[101] D. K. Chaturvedi, P. S. Satsangi, and P. K. Kalra, "Load frequency control: a generalized neural network approach,” Int. J. Electr. Power Energy Syst., vol. 21, no. 6, pp. 405-415, 1999.

[102] T. P. I. Ahamed, P. S. N. Rao, and P. S. Sastry, "A reinforcement learning approach to automatic generation control," Electric Power Syst. Res., vol. 63, no. 1, pp. 9-26, 2002. 
[103] T. P. I. Ahamed, P. S. N. Rao, and P. S. Sastry, "Reinforcement learning controllers for automatic generation control in power systems having reheat units with GRC and dead-band," Int. J. Power Energy Syst., vol. 26, no. 2, pp. 137-46, 2006

[104] T. P. I. Ahamed, P. S. N. Rao, and P. S. Sastry, "A neural network based automatic generation controller design through reinforcement learning,” Int. J Emerg. Electric Power Syst., vol. 6, no. 1, pp. 1-31, 2006.

[105] D. M. V. Kumar, "Intelligent controllers for automatic generation control," IEEE region 10th international conference on global connectivity in energy, computer, communication and control, vol. 2, pp. 557-574, 1998.

[106] A. Demiroren, N. S. Sengor, and H. L. Zeynelgil, "Automatic generation control by using ANN technique," Electric Power Comp. Syst., vol. 29, no. 10, pp. 883-896, 2001.

[107] H. L. Zeynelgil, A. Demiroren, and N. S. Sengor, "The application of ANN technique to automatic generation control for multi-area power system,” Int. J. Electr. Power Energy Syst., vol. 24, no. 5, pp. 345-354, 2002.

[108] A. Demiroren, N. S. Sengor, and H. L. Zeynelgil, "Automatic generation control for power system with SMES by using neural network controller,” Electric Power Comp. Syst., vol. 31, no. 1, pp. 1-25, 2003.

[109] H. Shayeghi, and H. A. Shayanfar, "Application of ANN technique for interconnected power system load frequency control," Int. J Eng., vol. 16, no. 3, pp. 247-254, 2003.

[110] H. Shayeghi, and H. A. Shayanfar, "Application of ANN technique based on $\mu$-synthesis to load frequency control of interconnected power system,” Int. J. Electr. Power Energy Syst., vol. 28, no. 7, pp. 503-511, 2006.

[111] L. C. Saikia, S. Mishra, N. Sinha, and J. Nanda, "Automatic generation control of a multi-area hydrothermal system using reinforced learning neural network controller,” Int. J. Electr. Power Energy Syst., vol. 33, no. 4, pp. 1101-1108, 2011.

[112] Y. Oysal, "A comparative study of adaptive load frequency controller designs in a power systems with dynamic neural network models," Energy Conv. Manag., vol. 46, no. 15-16, pp. 2656-2668, 2005.

[113] N. P. Padhy, Artificial Intelligence \& Intelligent Systems. Oxford University Press, 2005.

[114] V. Vapnik, Statistical Learning Theory. New York: John Wiley, 1998.

[115] L. Jaing, M. Deng, and A. Inoue, "Obstacle avoidance and motion control of a two wheeled mobile robot using SVR technique," International Journal of Innovative Computing Information and Control," vol. 5, no. 2, pp. 253 262, 2009.

[116] C. Manop,V. Kinnares, and S. Chunwiphat, "SVM-based stator fault diagnosis for induction motors using dq voltage components," International Journal of Innovative Computing Information and Control, vol. 6, no. 11, pp. 4539-4553, 2010

[117] J. A. K. Suykens, T. Van Gestel, J. De Brabanter, B. De Moor, and J. Vandewalle, "Least squares support vector machines", World Scientific, 2002.

[118] H. Tamura, and K. Tanno, "Midpoint validation method for support vector machines with margin adjustment technique," International Journal of Innovative Computing Information and Control, vol. 5, no. 11, pp. 4025-4032, 2009.

[119] D. Boolchandani, A. Ahmed, and V. Sahula, "Efficient kernel functions for support vector machine regression model for analog circuits performance evaluation," Analog Integr. Circ. Sig. Process, vol. 66, pp. 117-128, 2011.

[120] D. Boolchandani, L. Garg, S. Khandelwal, and V. Sahula, "Variability aware SVM macro model based design centering of analog circuits," Analog Integr. Circ. Sig. Process, vol. 73, pp. 77-87, 2012.

[121] J. A. K. Suykens, J. Vandewalle, and B. De Moor, "Optimal control by least squares support vector machines", Neural Networks, vol. 14, pp. 23-35, 2001.

\section{BIOGRAPHY OF AUTHORS}

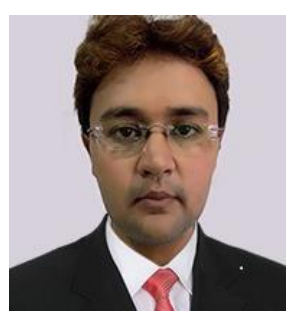

Dr. Gulshan Sharma is presently working as Senior Lecturer and Deputy Director of RTDS center in Department of Electrical Power Engineering, Durban University of Technology, Durban, South Africa. He has more than 10 years of teaching and research experience. He has the qualifications of B. Tech, M. Tech and Ph.D. from Punjab Technical University (Punjab), Jamia Millia Islamia University (New Delhi) and Malaviya National Institute of Technology (Jaipur), India. He was a Post Doctoral research fellow at Faculty of EBIT, University of Pretoria, South Africa from 2015 to 2016 . He has published a number of research papers in international journals and conferences of high repute and has been continuously engaged in guiding research activities at graduate/post-graduate and Ph.D. levels. His area of interest includes power system operation and control, renewable power generation and integration, smartgrid, electric vehicles, FACTS and application of AI techniques to the power systems.

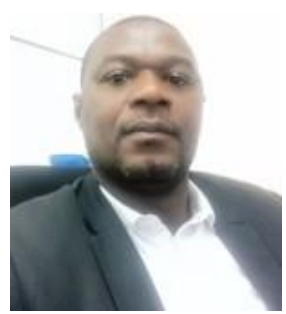

Kabulo Loji is since 2006 a Lecturer in the Department of Electrical Power Engineering at the Durban University of Technology in South Africa, after he has been in the industry since 1998 where he gained considerable field and design engineering experience. In 2004, hereceived his B-Tech Degree in Electrical Engineering at the Vaal University of Technology in South Africa and he is currently pursuing his M.Sc. qualification in Electrical Engineering at the University of KwaZulu-Natal in South Africa. His research interests lie in the areas of analysis, operation and control of power systens with emphasis on renewable energy sources penetration, andthe area of Engineering Education with special focus on Teaching for Learning in the engineering field. 